\title{
ENGLISH IN THE GLOBAL WORKPLACE: A NARRATIVE APPROACH
}

\author{
Emilia Wąsikiewicz-Firlej
}

\begin{abstract}
This paper aims to contribute to the discussion on the new directions in ESP education and revisit the concepts of the native speaker and lingua franca as seen from the lay perspective. It reports the results of a research study - an analysis of narratives of ten Polish professionals working for international organizations who share their experiences and tell stories on communicating and using English in the workplace. The narrative approach adopted in the study gives an insight into individual perspectives, facilitating an in-depth, holistic understanding of the studied matters. The findings have shown that native English is still deemed to be the main point of reference by the participants of the study and the notion of lingua franca appears unfamiliar and difficult to accept, especially in the educational context. Variations in individual preferences concerning communication with native or non-native users of English and declared comfort related to such interactions have been observed and correlated with the level of proficiency in English. In most cases, more proficient users have reported to feel more comfortable in interactions with native speakers of English. They have also demonstrated certain language awareness, which stands in a sharp contrast to the participants less proficient in English, whose perception of language is very simplified. As regards pedagogical implications, the study has signalled a need for sound cultural preparation of professionals working in international environment and a greater emphasis on developing communication skills for socialising - an essential aspect of business communication.
\end{abstract}

\section{Key words}

ELF, lingua franca, professional communication, workplace narratives

\section{Introduction}

One of the challenges for contemporary higher education is its relevance to the needs of the global workplace and ensuring students' employability. Language and communication skills of graduates are considered crucial for their future careers and professional success. As Victor (1992: 246) notes: "It is probably better to have mediocre technical skills and excellent international business communication skills than to have excellent technical skills and poor international business communication skills". English remains the dominating language of workplace interactions and its knowledge is taken for granted in international corporations that run their business activity in the international, 
multilingual and multicultural settings. The fact that the majority of professional interactions takes place globally between non-native users of English, poses an important question to ESP educators: which English to teach?

The present paper attempts to address this question and contribute to a growing body of research on the use of English as a Lingua Franca (ELF). The first part of this paper provides theoretical underpinnings to the use of ELF in the professional context. The first section defines the concept of lingua franca, followed by the discussion on the notions of English as a Lingua Franca, Business English Lingua Franca and Global Communicative Competence, undertaken in the next sections. Based on the constructed theoretical framework, a research study on the use of ELF by ten Polish professionals in workplace communication has been designed and conducted. The narrative approach has been adopted in the study and the data have been collected through in-depth interviews. The last sections of the paper report the results of the narrative analysis.

\section{The concept of lingua franca}

Our discussion on the use of English in the global workplace begins with a definition of the very concept of lingua franca. Basically, a lingua franca is a language used by non-native speakers (NNSs) to communicate with other NNSs, which remains foreign to both parties (cf. Vandermeeren 1999: 279). Although the concept has been defined in various ways, most scholars (e.g. Haegeman 2002, Meierkord 2002) concur with the ideas that "(a) lingua franca is spoken by non-native speakers who have to communicate for a particular purpose, and (b) the language used is somewhat 'reduced' from its NS [native speaker] usage" (Louhiala-Salminem \& Charles 2006: 30).

From the historical perspective, lingua franca is not a new concept. As Knapp and Meierkord (2002: 9) observe, originally the term was applied to a range of languages that was used in the South-Eastern Mediterranean region, mainly for the purposes of trade between representatives of various linguistic communities. The first lingua franca was a hybrid pidgin, probably based on Italian, and incorporating elements of Spanish, French, Portuguese, Arabic, Turkish, Greek and Persian (ibid.). Linguae francae might be either used on a small territory by trading communities, or be extended to larger areas as in the case of Latin used in the Roman Empire (Tietze 2008: 71). Also Rogerson-Revell (2007: 104) asserts that the use of any language as a lingua franca by speakers of different languages was primarily motivated by business purposes. A very illustrative support of this argument might be found in the fact that the word pidgin is a mispronounced Chinese version of the English word business and the name Pidgin English 
was used to refer to "a Chinese-English-Portuguese pidgin used for commerce in Canton during the $18^{\text {th }}$ and $19^{\text {th }}$ centuries" (ibid.). However, a real need for adopting a shared global lingua franca emerged in the twentieth century when a range of international institutions and organizations was set up and the number of international business and academic contacts significantly increased (Crystal 2003).

\section{English as a Lingua Franca}

Nowadays the position of the global lingua franca is indisputably held by English (Louhiala-Salminem \& Charles 2006, Crystal 1997, Dovring 1997, Cenoz \& Jessner, 2000), labelled in literature as English as a Lingua Franca ELF (e.g. Seidlhofer 2001, 2004, Jenkins 2004, 2012, Knapp \& Meierkord 2002). The beginning of the emergence of English as the global language might be dated back to the $16^{\text {th }}$ century and the first voyages to America and Asia, which were significantly reinforced in the $18^{\text {th }}$ and $19^{\text {th }}$ century by British colonialism and imperialism, respectively (cf. Crystal 2003, Ostler 2005). Initially, the English language was strongly linked to the trade and business; however, later on it penetrated the political domain, becoming an official or semi official language of the British colonies. In the $20^{\text {th }}$ century, along with the domination of the United States in the global political and economic arena, English pervaded almost all domains of human activity, e.g. the media, entertainment, commerce, science and education, enabling the flow of knowledge across national and cultural barriers and changing the quality of human perception and experience (cf. Tietze 2008).

Scholars, however, express some disagreement concerning the very definition of ELF. For example, Firth (1996) and House (1999) perceive ELF as the language used by non-native speakers (NNSs). Others, e.g. Llurda (2004), Seidlhofer (2004), Jenkins (2007), opt for using ELF as an umbrella term, which does not exclude interactions between NNSs and native speakers (NSs) of English. In Jenkins's (2007) and Seidlhofer's (2004) view, ELF should include NSs of English, nevertheless, they should be excluded from data collection when interacting with NNSs as they "do not represent a linguistic reference point" (Jenkins 2012: 3). However, bearing in mind the fact that "statistically native speakers are in a minority for language use (...)" (Brumfit 2001: 116), this paper's orientation is in line with the view supporting the inclusion of NSs in ELT. Limiting the application of the term only to the language used in nonnative interactions would seem rather artificial. In reality, English is the working language of various meetings or conferences, frequented by both native and nonnative speakers. For this reason, in natural settings both types of interactions (NSs-NNSs and NNSs-NNSs) occur. 
Despite the fact that the legitimacy of ELF is poorly recognized by scholars, the phenomenon deserves an in-depth scrutiny as it poses new challenges to ELT. In the past decades, the main aim of ELT was developing a near-native competence "(...) with the "native speaker' ... as the point of reference" (BruttGriffler 2002: 179). The position of the native speaker was privileged and it was assumed that FL users or learners aimed at being affiliated with the community of NSs were affected by this community but did not affect it by themselves (ibid.: 179-180). Nowadays, however, the reference point for FL learners and users has been shifted towards the intercultural speaker (Kramsch 1998: 17), and the very term of the native speaker has become rather controversial. It has been criticised as a vague and idealised concept. This criticism was initiated in the 1980 s by Thomas Paikeday (1985) in his self-published book The native speaker is dead and then taken up by others (e.g. Kachru 1985, Widdowson 1994). Kramsch (1998: 27) observes that in contemporary multicultural and multilingual world adapting language to a given context rather than complying with restrictive norms appears the key skill. Therefore, Kramsch (1998) recommends revisiting the aims of FL pedagogy by abandoning the well-grounded model of educating a near-native FL user and substituting it with a model which aims at forming the intercultural speaker who is aware of their own cultural identity as well as cultural diversity of their interlocutors (ibid.). The ideas promoting integration of language and culture skills were also put forward by Byram and Cain (1998), who perceived culture as an indispensable element of FL education. Byram's ideas (1997a, b) were widely echoed in Europe - especially his ICC model - and had a real influence on the development and implementation of FL education policy in the EU (cf. Council of Europe 2007).

\section{Business English Lingua Franca (BELF)}

Due to globalisation and dynamic development of technology, the use of ELF is observable in all walks of life; however, its presence is most visible in professional settings. English has become indispensable in business communication and its dominance as a lingua franca of international business contacts is unquestionable (Bargiela-Chiappini 2006, Nickerson 2005). Nowadays, any business or professional activity involves numerous international contacts and interacting with representatives of different cultures. Accordingly, "English is a high priority for management in most companies" (Bloch \& Starks 1999: 86). In the global workplace, people with different cultural and linguistic backgrounds are expected to work efficiently for the common goals of an organization or an institution they represent. To make communication between 
people with different cultural and linguistic backgrounds possible, professionals mostly use ELF for their workplace interactions. Thus, proficiency in English is perceived as a must, especially in international corporations (Louhiala-Salminen \& Kankaanranta 2011).

In business communication ELF has been given various labelling, e.g. "International English for Business Purposes" or "International Business English (IBE)" (Barlett \& Johnson 1998). However, since this paper oscillates around the concept of lingua franca, the use of the Business English Lingua Franca (BELF), proposed by Louhiala-Salminen, Charles and Kankaanranta (2005), seems more appropriate. BELF is understood as a "code" for doing business and it takes as its reference point not "an ordinary native speaker" but "an ordinary businessman", both being rather vague concepts (Louhiala-Salminem \& Charles 2006: 31). It also emphasises the idea that the language ownership is not ascribed to NSs - it is shared by its users. Thus, all BELF speakers enjoy equal status of communicators who use a foreign language for their common work-related purpose(s).

An important aspect of BELF use for professional purposes is the cultural background of its speakers. It would be too simplistic to assume that BELF interactions are culture neutral. In fact, all interactants bring in a diversity of their cultural background, understood not only in terms of national variability, but also their professional, corporate or even departmental culture, as well as their personal traits and experience. For this reason, they apply different rules both explicit and implicit - to decode and encode messages. Louhiala-Salminem and Charles (2006: 32) suggest that in lingua franca interactions instead of applying the rules of their mother tongue, communicators use a "code" or "contact language" that they have learnt. Thus, at the lexical and grammatical level, signs would be interpreted by communicators in accordance with the rules of the English language. However, at the pragmatic level such interpretation appears far more intricate and it could be facilitated by other factors such as, e.g. common business knowhow, beliefs and understanding of a particular situation.

\section{Global Communicative Competence}

A significant contribution to the discussion on communicative competence in multilingual and multicultural settings (including workplace) has been offered recently by Finnish organizational communication researchers - LouhialaSalminem and Kankaanranta (2011) - who have introduced the notion of Global Communicative Competence (GCC). The notion encompasses three elements: multicultural competence, competence in English as Business Lingua Franca (BELF) and communicator's business know-how (ibid.: 246). Although 
competence in English as a Lingua Franca (ELF), the dominating language of global communication, involves the knowledge of the rudiments of the English language or the "core", using Jenkins's (2007) terminology, it primarily "focuses on interactional skills, rapport building, and the ability to ask for and provide clarifications" (Louhiala-Salminem \& Kankaanranta 2011: 246).

The proposed theoretical GCC model has been applied in a research study conducted in five multinational corporations operating in Finland on the sample of 987 respondents. Multicultural competence is understood in this model as interlocutors' adaptation skills and flexibility in interacting with representatives of various cultures. According to the respondents who participated in the study (Louhiala-Salminem \& Kankaanranta 2011), the importance of national culture in professional contacts is overweighed by organizational culture of a particular workplace, correlating positively with the quality of personal relations and work effectiveness. The results of the study have shown that the English language proficiency is regarded as one of the key skills required at work. Nevertheless, it has been emphasized in the study that the main determinant of successful professional communication is not a mastery of grammar but specialist vocabulary and related genres. Thus, grammar and vocabulary should be sufficiently good to enable reasonably effortless communication (ibid.: 253). Finally, the respondents pinpointed to the importance of listening skills and an ability to recognize various accents of English while interacting with other users of ELF. Furthermore, successful communication was defined as effectiveness in completing tasks and achieving professional goals.

In conclusion, the use of EFL is considered efficient as long as interlocutors are familiarized with the rules of business activity and have specialist knowledge of a particular professional field. Therefore, communicative competence might be considered as an essential component of general professional competence.

\section{Criticism}

A range of studies (e.g. Firth 1996, Haegemann 2002, Lesznyak 2002, Louhiala-Salminen et al. 2005, Poncini 2004, Vourela 2004) confirm the "collaborative and consensus-oriented nature of lingua franca discourse" (Louhiala-Salminem \& Charles 2006: 35). Nevertheless, Seidlhofer (2004) perceives the success of BELF discourse with some reservations, mainly due to a lack of sufficient evidence from research. Certain scepticism is also voiced by House $(1999,2002)$, who questions conversational cooperation in lingua franca interactions, suggesting that the declared consensus might be illusionary and mask real problems or misunderstandings. 
Furthermore, some scholars (Bowers 1986, Block 2002, Gray 2002, Gee 1996, Phillipson 1992) have also challenged the neutrality of ELF as a communication vehicle, mainly on the grounds of power-related and ideological issues. As Tietze (2008: 65) observes, numerous scholars researching the use of English in the global context highlight its controversial nature as a lingua franca. ELF is seen as a tool for propagating certain ideology (e.g. ideas, values and terminology originated in the USA and Britain), executing power and expressing differences among particular agents in an organization.

In Tietze's (2008: 89) view, English gives an advantage to professionals, politicians, artists or academics, and its mastery appears one of the most decisive factors contributing to an individual's professional success or/and social position. Thus, the choice of language can even be considered in terms of "winners and losers" (ibid.). Another important determinant, often ignored by some ELF advocates, is the level of proficiency, providing a privileged position to native speakers of English or its most proficient users. According to Schneider and Barsoux (2001: 232):

The very fact that English has become the lingua franca of business reinforces these power issues; thus Anglophones, those most likely to preach empowerment or to favour brainstorming; tend to dominate group discussions ignoring that the differences in ability to speak English create an unequal playing field.

For this reason, Tietze (2008: 68) even proposes a shift from the "cultural differences" to "language differences" approach. Appreciating the role of ELF in facilitating professional communication and knowledge transfer, Tietze (2008) simultaneously identifies some problematic areas such as, for example, differences in proficiency levels, which might lead to miscommunication, as well as power-related and ideological issues, understood in terms of unequally distributed access to education and postcolonial and capitalist legacy. However, in opposition to the "linguistic imperialism" concerns, voiced by, e.g. Pennycook (1998) or Canagarajah (1999), Seidlhofer (2000) takes a more pragmatic view and argues that:

ELF speakers are ... not primarily concerned with emulating the way native speakers use their mother tongue within their communities, nor with sociopsychological and ideological issues. Instead, the central concerns for this domain are efficiency, relevance and economy in language learning and language use. (...) people want to learn English whatever the ideological baggage that comes with it (...). (Seidlhofer, 2000: 57). 
This approach is, in fact, often taken by business practitioners (RogersonRevell 2007: 108).

The controversies concerning the use of ELF in international business communication demonstrate that the concept still requires further theoretical and empirical investigation, providing a good rationale for further research.

\section{The use of English in professional communication: A research study}

\subsection{Aims and context}

Addressing the need for further research signalled in the previous sections, a research study on the use of ELF in professional communication has been designed. The main aim of the study has been to verify the concept of ELF from the lay perspective in the context of real experiences of ten Polish professionals working for international organizations. Following House's (1999, 2002) scepticism, the main assumption underlying this study is that comfort and satisfaction with the use of ELF for professional communication declared by non-native speakers may be a result of low language awareness and low language proficiency. The theoretical framework adopted in this study is that of folk linguistics, incorporating the accounts of "what people say about reactions to language" (Niedzielski \& Preston 2003: 29). In order to analyse the stories on the workplace language use, shared by the participants of the study, the narrative approach has been taken, discussed in the following section.

\subsection{Method}

\subsubsection{Research approach}

The very term narrative has Latin etymology (narratio) and stands for a story. According to Moen (2006: 3): "A narrative is a story that tells a sequence of events that is significant for the narrator or her or his audience". Looking at the narrative through the lens of sociocultural theory, it should be highlighted here that an individual's stories are firmly set in a particular sociocultural context that needs to be taken into consideration during the interpretation process.

Telling stories is an essential part of human existence, helping to structure our experience and making it meaningful. Apart from producing our own narratives we are also exposed to numerous narratives of others; thus, sharing stories has a social aspect (Zellermayer 1997). Riessman (2008) asserts that creating and sharing narratives is universal, and surpasses the locational, social or age barriers. Stories reflect a particular sociocultural and historical context from which they 
arise and have an interacting potential, involving both narrators and listeners (Elliot 2005). Polkinghorne (1988) suggests that everybody has a story to tell. In Moen's (2006) view, "life itself might (...) be considered a narrative inside which we find a number of other stories".

The narrative approach is a relatively new field with the qualitative or interpretive research tradition, which has gained more and more interest in recent years, tangible in the growing body of literature on the theme. The foundations of the narrative approach might be traced back to the sociocultural theory, Vygotsky's (1978) developmental ideas and Bakhtin's (1986) concepts of dialogism and heteroglossia. Since the main aim of narrative studies is to scrutinise human experience, narrative researchers collect and write such stories (Gudmundsdottir 2001). This approach offers researchers in-depth understanding of individual perspective of their research subjects who reflect on their experiences and enables them to organize fragmented chunks into the meaningful whole, reflecting the complexity of life and avoiding simplification (Eliot 2005, Riesmann 2008).

The interpretation of the concept of narrative in research varies among scholars. It is, for example, used in the context of representation of a qualitative study (Moen 2006). Within this approach, "a case study, a biography, a phenomenological or an ethnographic study may have a narrative form of representation" (Moen 2006: 2, after Cresswell 1998). Other researchers perceive the narrative approach as a research method (e.g. Connelly \& Clandini 1990, Gudmundsdottir 2001). This view is, however, negated by some scholars who qualify the narrative approach as a frame of reference rather than a method and postulate that narratives both create and reflect reality (Heikkinen 2002, referred to in Moen 2006). However, the perspective taken in this paper follows that of Moen's (2006: 2), who incorporated all three approaches, categorising the narrative approach as "a frame of reference, a way of reflecting during the entire inquiry process, a research method, and a mode for representing the research study".

\subsubsection{Data collection}

The data collection method was semi-structured, in-depth interviews. Indepth interviews produce a uniquely personal kind of data, and enable profound insight into experiences, feelings and underlying attitudes (May 1993, Patton 1987). Each participant was interviewed twice personally by the author of this paper. The aim of the first interview was to diagnose each participant's level of proficiency in English, which involved self-assessment and an application of an online placement test, followed by a diagnosing enquiry. During the second meeting, in the beginning of the second interview, the participants were asked 
to tell their stories concerning the use of English in the workplace, starting at any point they wanted. The questions asked by the interviewer were meant to stimulate respondents to reflect back on their careers and share their experiences concerning the use of English for professional communication along with their interpretation in the form of a narrative. Additionally, participants were asked to self-evaluate their language skills and reflect on the possible needs and directions of their improvement. All the interviews were taped in order to listen to the respondents in an active and concentrated way, and afterwards fully transcribed. All interviews were held in Polish and lasted from thirty to forty-five minutes. They were recorded, transcribed verbatim and translated into English. Simplified transcription conventions were used (cf. Appendix 1), based on the premise that contrary to the principles of conversation analysis, "the notations used by interpretive analysts tend to be minimal" (Boje 1991: 112).

\subsubsection{Participants}

Since current research has mainly focused on the use of ELF in the business context, the main criterion for selection included participants representing various fields of professional activity. Consequently, in order to account for the diversity of professional uses of ELF maximum variation sampling was adopted in the study, which involved selecting "cases with markedly different forms of experience" (Dörnyei 2007: 128). The participants in the study were ten professionals representing different organizations and fields of professional activity (cf. Table 1). The identity of participants and their organizations remained anonymous. The participants' demographic details and their levels of English proficiency have been presented in Table 1 below.

\begin{tabular}{|l|l|l|l|l|}
\hline Respondent & Gender & Age & Professional field & Level of English proficiency \\
\hline 1 & M & 35 & R\&D & C1 \\
\hline 2 & M & 42 & Banking & B2 \\
\hline 3 & M & 58 & International sports association & B1 \\
\hline 4 & F & 37 & Sales & C2 \\
\hline 5 & M & 42 & Tourism & B1+ \\
\hline 6 & F & 37 & Accounting & B2 \\
\hline 7 & M & 36 & Finances & B2 \\
\hline 8 & M & 62 & Sales & C2 \\
\hline 9 & M & 25 & Marketing & C1 \\
\hline 10 & F & 37 & PR & C2 \\
\hline
\end{tabular}

Table 1: Participants' data 


\subsubsection{Data analysis}

After having being transcribed, data in the written format were subjected to content analysis. Systematic data analysis does not limit the researcher's role to collecting and reporting participants' stories but helps to assign meaning, which usually leads to a range of findings. The procedure for inductive content analysis developed by LeCompte, Preissle and Tesch (1993) was followed in this study. It involved three basic steps: reading and re-reading all the data, identifying recurring ideas and classifying these ideas into themes.

\subsection{Results and discussion}

The main themes that emerged from the data have been classified into the following categories: perceived communication comfort and problematic areas, socialising, culture, power related issues and career prospects. All interviewees reported that in their daily workplace communication practices they interacted both with native and non-native speakers of English that involved oral and written forms of communication. The use of particular professional genres was, however, limited to meetings, conferences and telephone conversations in the case of oral communication, and email messages as the dominating written genre.

\subsubsection{Perceived communication comfort and problematic areas}

One of the most frequently emerging themes in the analysed narratives was the perceived comfort of communication with native versus non-native speakers English and possible problematic areas. This perception was by definition highly subjective and participants' opinions varied. However, a certain pattern of preferences could be observed. Namely, participants more proficient in English tended to perceive interactions with NSs as more comfortable and paid special attention to the prosody of language and nonverbal cues - the elements of communication that were not mentioned by less proficient participants. For example, one of the participants, an experienced, retired sales manager (P8) with rich international corporate experience, regarded these elements as crucial for successful business:

In business these are not always words that matter. You have to read between the lines... pay attention to intonation, the choice of words, mimics, gestures. You can interpret messages properly if you have mastered the language. When somebody uses broken English I can talk about facts and figures but I don't have a feeling that I'm doing business properly ... for example, during negotiations it is difficult to find out the real intentions of the other party if you need to focus on understanding wrongly pronounced words. (P8) 
Pronunciation was, in fact, identified as the most problematic aspect of communication with NNSs, especially of Asian origin, in contrast to imperfect use of grammar, which was not seen as a communication barrier. One of the participants (P1) - a researcher, resident of the UK, working in the international environment for over a decade - worded it in the following way:

I think that the most important thing is pronunciation. I have never been taught proper pronunciation. The English recognize that you are Polish or East-European immediately ... ${ }^{* * *}$ I think sometimes natives do not understand me. It might be related to the region... in London I believe I had fewer problems. ${ }^{* * *}$ It is definitely far more difficult to communicate with NNSs of English. Each of them has a different pronunciation and you often have to work out what they are saying and what that really means. For me the most difficult to understand is Chinese and Indian English. *** Pronunciation is in my opinion the most important thing. To communicate with someone you don't really have to pay much attention to grammar. It doesn't help when someone speaks grammatically perfect English and you can't understand a thing because of pronunciation. *** I have observed recently that the English of the natives is getting simpler and simpler. I am not sure if it is a general phenomenon or they just do it so that the others can understand them. ${ }^{* * *}$ My reference point is always native English. (P1)

Acceptance of grammatical incorrectness and difficulty with Asian accents was also expressed by Participant 4 - a graduate of English philology currently working as a key account sales manager:

It is fine with me if somebody uses bad English, makes grammatical mistakes ... specially when dealing with customers from Europe ... I got used to their accents. Still I feel much more comfortable interacting with NSs ... we can joke, laugh, play with the language. Obviously, I need some time to get used to some regional native dialects. Asians are sometimes incomprehensible to me. (P4)

Another English philology graduate (P10), currently working as a PR manager, even expressed discomfort related to some of her interactions with NNSs with low level of proficiency in English.

It really makes a difference when I communicate with NSs. In a positive sense, obviously. When somebody's English is really bad I need to follow every word, sometimes deciphering its meaning because of bad pronunciation and then work out the meaning. It is so exhausting sometimes ... I often leave such meetings with a terrible headache, often confused. (P10) 
More proficient participants (P1, P4, P8, P10) report, however, certain difficulty in understanding some dialects of English. For example: "I don't really experience any misunderstandings at work. I have sometimes problem understanding local dialects in everyday life situations. At work NSs try to use the standard. But in the street it might be difficult - especially in Manchester or Liverpool." (P1)

Nevertheless, quite different stories were shared by participants with lower levels of proficiency in English, who generally declared their preferences to communicate with NNSs. For example, Participant 3, who started learning English over the age of fifty and managed to achieve B1 level, communicates successfully in English with other NNSs in international professional settings but signals certain limitations in the use of English to interact with NSs.

When I communicate with NNSs I have a felling that my grammar is no problem ... they do understand me. I think it is an accepted norm to use infinitives ... we tend to ignore tenses. I have absolutely no problem communicating in everyday situations: at the hotel, airport. With natives it is a different story... the language is more complex. ${ }^{* * *}$ With NNSs it is easier because we learn from similar course books. But your preferences depend on your level of English ... if you are more advanced like my daughter - she studied in the US - she might prefer to speak to natives. But it is a different story; she uses a different language, has a different pronunciation." (P3)

Similarly, Participant 2, representing the banking sector, declared to feel more comfortable in interactions with NNSs, believing that ignorance of grammatical rules and shared specialist vocabulary is sufficient to communicate at the workplace. Nevertheless, he seemed to be aware of the fact that NSs simplify their language to communicate with NNSs.

When I talk to NNSs I don't need to control myself ... I feel more relaxed. Who cares ... we all make mistakes. We all know some banking terms and do not worry about grammar. The natives also try to adapt to our level, simplifying their language. If there are more NSs at a meeting talking to each other, then I'm in trouble. It's difficult to follow them. (P2)

Interestingly, Participant 3 is aware that his high position in the organizational structure and the level of formality enable him to control the whole process of communication and make him feel comfortable irrespective of his poor language skills. 
For me it's easier to communicate in formal situations. I am always well-prepared. My position is also important. I chair meetings so it's all up to me ... I specify the agenda. *** At meetings, in more formal situations, we try to use better English... I am always well-prepared for meetings... have everything written down, prepare handouts. But when I don't control it, in more informal situations, I have a feeling that people ignore the rules of the English language and apply the rules of their native language.

Based on the participants' narratives, personal preferences to communicate with native or non-native speakers seem to be to a great extent related to individual English proficiency levels. Participants with low linguistic competence also show low language awareness; they tend to ignore the importance of the rules of grammar and reduce workplace communication to the exchange of commonly shared professional vocabulary. This stands in a sharp contrast to reflections on the workplace language of more proficient participants who use language more creatively, play with it, joke and, above all, are aware of its phatic function, crucial in building and maintaining relations, thus essential to successful business. Additionally, they are also aware of the importance of prosody and nonverbal communication, which enable them to interpret messages holistically.

\subsubsection{Socialising}

Socializing is regarded as a part and parcel of professional life, crucial to building and maintaining relations. Linguistically, though, it might also come across as the most challenging aspect of professional communication, especially when interacting with native speakers. Social interactions are less controlled and predictable; they involve more diverse language use and a wider thematic scope than strictly professional ones. For these reasons, socializing might pose a certain difficulty to less proficient language users.

When we socialize with NNSs and we are short of English words we simply use words from our native languages: Polish, Italian, and Spanish. We understand each other and accept our mistakes. At parties, though, at bigger events, we usually socialize within national groups. We rarely talk face to face to natives. (P3)

As one of the participants (P2) observed, on formal occasions NSs simplify their language for the sake of professional communication purposes but in informal situations they switch the code which is often difficult to understand by less proficient language users. 
These conferences are attended by native speakers but ... you know... they're trying to change their language... simplify it ... they try to change their habits. Yeah... the language of conferences is generally simplified. But if you go out with natives the language they use is of course different. They switch to their real language when they interact with other natives they are really difficult to follow. Sometimes I simply give up and join my Polish colleagues. (P2)

Thus, poor language skills negatively affect both the quality and quantity of social interactions, highly appreciated and enjoyed by more proficient participants. As one of them (P8) stated:

What I used to love about my job were these informal meetings. I had a feeling that the real business was done during our lunches or evening outings. Socializing with a person whose English is limited to business vocabulary is no fun. You need to talk about things other than business ... this is how you get to know a person and make a good deal. I realize it has changed now. Relationships are not as important as they used to be ... with some clients I worked for two decades or so ... we were on very friendly terms. Now people come and go ... they do not make such strong bonds. I am really happy I am retired now ... (P8)

Similarly, Participant 10, a proficient user of English, expressed her satisfaction with socialising at work: "Socialising is the best part of my job. I love travelling and meeting new people. When you meet someone face to face it is easier to work together afterwards". (P10)

Finally, Participant 4, another proficient user of English, reported that socialising with native speakers might be indeed challenging as it requires high language proficiency levels.

After general meetings or international conferences we usually have a party. The English and Irish usually flock together. At first, most people want to stick to them but you clearly see that they do not really follow when their conversation speeds up. They often miss the punch line. After a while, most of them give up and find somebody else to talk to. At such moments I'm really happy that I majored in English. It really makes a difference. [LAUGH] (P4)

Additionally, Participant 4 also observed that in order to remain proficient in English its use cannot be limited only to business related issues. "For everyday communication at work I don't feel any need to work on my English. But I have noticed that I tend to forget words not related to my work". (P4)

Socialising usually involves the use of humour that does not only require the mastery of language, but also familiarity with the cultural context. Informal 
occasions also inspire conversations on a countless number of topics, not always related to work matters. This entails knowledge of rich general vocabulary as well as familiarity with culture-related issues.

\subsubsection{Culture}

Except for BELF competence, other elements of GCC model, essential to successful professional communication in the global setting, include multicultural competence and business knowhow. Culture-related themes were identified in most of the analysed narratives. Surprisingly, despite their rich intercultural experience the interviewees reported not to have been provided with any form of intercultural training. Their knowledge in that respect is based mainly on their own experience. For this reason, the interviewees perceive representatives of other cultures and interpret their experiences through the prism of stereotypes deeply enrooted in their own cultural circle. This is bound to lead to a simplified perception of other cultures and fossilisation of existing stereotypes. The East and West cultural division appears one of the most frequent motifs in the narratives:

Culture in Europe is not a problem. I think that we - the Western civilization - are more or less the same. I haven't had any serious problems. (P2)

In the UK cultural differences are not a problem. In Asia obedience ... individualism is a problem. You are not expected to have your opinion; you just have to follow your superiors' orders." (P1)

Such presumptions might lead to a false conclusion that cultural variability is insignificant in the European context, at the same time maximizing the cultural gap between Europe and Asia and forming biased attitudes.

Another commonly shared stereotype concerns cultural differences between Northern and Southern Europeans. Basically, Southerners are perceived as more open, approachable and outgoing in contrast to reserved Northerners. Based on his own personalized intercultural experience, limited mostly to contacts with Spanish, Italian and occasionally American co-workers, one of the participants considers the British as the paragon of moderate openness that should be imitated by other users of English.

In Europe you can distinguish the southerners from the northerners. Your conversations with Scandinavians are short and to the point. Their English is very good. The Italians and Spanish talk for hours but they reach short conclusions. I am somewhere in-between. I personally prefer the northern style ... I am rather technically-oriented... and this is how I communicate... but interactions with southerners are very, very pleasant ... they will tell everything about their wife, 
children... but the basic aim of communication is always there. The Brits are somewhere in-between and this should be the target of international contacts: being not too closed and not too open. The golden rule. (P3)

By contrast, the participants more proficient in the English language tend to avoid such generalizations and seem to be more aware of the influence of culture on communication processes. Additionally, their higher language proficiency allows them to understand the intricacies of language and helps them identify their own limitations. For example, Participant 1 reflects on his difficulty to understand humour and attempts to identify elements of culture which hinder it:

When you go out with natives you often understand every single word but without common cultural background you don't really touch the base ... you didn't see the same films, cartoons ... can't tell the same old jokes ... have no common childhood heroes, school problems... you went through a different system of education. This is in my opinion the most important fitting-in factor ... sometimes everybody is laughing and I don' know why. (P1)

\subsubsection{Professional knowhow vs. communication}

All participants identified the importance of professional knowhow as a factor facilitating their professional interactions in English. Thus, business knowhow and communication go hand in hand and are both essential to achieve professional goals: "Communication is much more important than anything else in business." (P2); or "At work the most important thing is to get the message across. The way you do it is less important than the message itself." (P4)

Professional knowhow shared by participants of communication enables them to communicate effectively for professional purposes even in the case of those with poor language skills:

But they [sailing association meetings] ....are not difficult to follow ... they concern sailing so we all specialize in it ... when we talk about the construction of the sail, for example, grammar doesn't matter. We all know what it is all about. We all know the vocab ... the knowhow is as important as language. (P3)

Those less proficient in English focus on the content of the message; they want to convey and show high levels of satisfaction with communication, ignoring the subtleties of language and paralanguage. Still, in certain professional contexts poor language skills seem to be a barrier that can be quite easily overcome. 


\subsubsection{Language, power and career prospects}

One of the main assumptions made in this paper is that ELF is not a neutral vehicle of communication and its use in professional context reinforces the power issues. In other words, it still privileges the native speakers of English and those more proficient in it, empowers them and offers better career prospects (cf. Schneider \& Barsoux 2001).

As five of the analysed narratives imply, in the organizational context less proficient users of English might become the butt of jokes, mainly due to their heavy national accents, mispronounced words, grammatical or lexical errors. These imperfections are not, however, discussed or derided at in public. During meetings all participants' faces remain straight, especially if mistakes are made by a person in power. The real comments appear in private and are often incorporated into an organizational set of anecdotes passed on to others. The extract below illustrates how people react to their co-workers' mistakes and how they evaluate their competence:

Let me give you one example how we communicate at work... today we had a sales meeting that was participated by one Irishman, two Dutchmen and the other were all Polish. It was chaired by my boss who is 61 and thinks she speaks perfect English ...*** the meeting was held in English. *** The Irish guy spoke English naturally but nobody understood him ... most people just could get the gist of his talk... he is my supervisor... you could easily understand the Dutch ... grammatically correct... unfortunately, the others spoke not very well really... what's common nowadays is that everybody tries to sound good phonetically ... but it is their own understanding what sounds good in English. [LAUGH] they, for example, palatalize consonants completely mispronouncing words... it is ridiculous but people are buying it. It reminds me of this Polish comedy when an airport worker filled her mouth with potatoes to speak English [LAUGH] yeah ... for example, they use the wrong stress pattern in the word difficult ... but ' $d$ ' and ' $t$ ' sounds are soft. It is some sort of mannerism. They twist their mouth as if they were eating flies. Two guys speak in this way. The others understand them perfectly and everybody is really satisfied with their English. American style [LAUGH]. (P4)

These observations concur with the doubts raised by House (2002) concerning the collaborative nature of ELF and its consensus-orientation. As Participant 4 suggests, the consensus and overall satisfaction with communication might be false due to the lack of understating on the part of some participants of interaction. People often declare to understand something or agree on something in order to avoid any form of confrontation or not to lose face. These factors are undoubtedly power-related, since revealing one's incompetence might put one's 
status in an organization in jeopardy. Thus, as Participant 4 further explains, employees avoid admitting openly their comprehension problems and resort to more subtle means of getting informed, such as, for example, verification of their knowledge through private conversations and summary emails.

We have an Irish boss. People have problem understanding him. In the beginning I had to get used to his English ... now it is OK but after meetings people leave the room confused ... except for me and our HR manager who speaks a very good English ... she sounds really good ... has good phonetics... the others need the feedback... a summary email. The point is that they would never admit they have problem understanding anything. Sometimes when we discuss things related to the meeting you see they have no idea about them. But they would never admit it. (P4)

In extreme cases, making up for one's ignorance might take a form of versatile avoidance strategies:

People use funny strategies to make up for their ignorance. I used to have a boss who would giggle any time she did not get something. To shorten the conversation with the Irish guy and be left alone she brought him some food, like dumplings - his favourite - to fill his mouth [LAUGH] Really! It's our work anecdote. She couldn't understand anything really... (P4)

These extracts and other accounts of participants' experiences contained in the analysed narratives, along with their declarations that proficiency in English has a significant influence on one's career prospects and organizational status, signal a need for further investigation of power-related issues and professional use of ELF.

\section{Final remarks}

The narratives under study have shown that, referring to Paikeday's (1985) catchphrase, the native speaker is not dead. The participants still regard native English as their main point of reference in their communication practice, finding the notion of lingua franca unfamiliar and difficult to accept in the educational context. Individual preferences concerning communication with native or nonnative users of English varied between participants, depending to a large extent on their level of proficiency in English. In general, more proficient users have reported to feel more comfortable in interactions with NSs. Additionally, they also demonstrated certain language awareness, in contrast to the participants less proficient in English, whose perception of language was very simplified. 
The most problematic areas identified by the participants in their professional communication practice include pronunciation, regional dialects, and Asian varieties of English. Furthermore, less proficient users of English have signalled their difficulty in effective socialising, perceived as an integral part of professional life.

Culture appears another important issue that has emerged in the study. Even though the participants are aware of cultural differences and their effect on communication and relation building, they have not received any specialist (inter)cultural training. Their knowledge is mainly based on stereotypes, which are further reinforced. Relying on fragmented individual experience might lead to the formation of biased attitudes and provides very subjective and limited perspectives. The study has also implied a need for sound cultural preparation of professionals working in international environment. A systematized cultural training would help professionals to understand the mechanisms of stereotype formation, equip them with sound knowledge and show national cultural trends, as well as personal variation. In other words, it would help them to construct and deconstruct their cultural knowledge.

The narratives have also shown that ELF's collaborative or consensus oriented nature cannot be taken for granted. English as a commonly shared global language is not only used to facilitate cooperation in the international settings, but also to build and reinforce the existing organizational hierarchies, and simply to gain power and control. Importantly, the achieved mutual understanding might be sometimes illusory and declarative, due to insufficient proficiency in English as well as a lack of language awareness, and thus interpreted as a strategy to prevent losing one's face. These aspects of professional language use have been so far rarely undertaken by scholars and need further exploration.

The narrative itself has turned out to be a very insightful research method, providing both the researcher and the participants with a holistic understanding of the matters under investigation and helping to understand the narrator's experiences, order and interpret them, and finally inspire reflections. The feedback obtained after the study has, in fact, come as a surprise; the participants felt a need to share other stories and experiences, gave examples of ELF communication and declared a fuller understanding of the processes and mechanisms underlying their daily communication practices.

In conclusion, the study has shown that individual perspectives might significantly differ from general trends. Even though personal stories cannot be regarded as representative, they significantly contribute to the holistic understanding of certain phenomena and show directions for further studies. Finally, this paper also advocates taking a less hurrah-optimistic position towards 
ELF for professional communication. Before reforming educational frameworks or announcing new trends, the matter needs to be soundly investigated and critically discussed.

\section{References}

Bakhtin, M. (1986) 'The problem of speech genres.' (V. McGee, Trans.). In: Emerson, C. and Holquist, M. (eds) Speech Genres and Other Late Essays. Austin: University of Texas Press. 60-102.

Bargiela-Chiappini, F. (2006) '(Whose) English(es) for Asian business discourse(s)?' Editorial. Journal of Asian Pacific Communication 16/3, 1-23.

Barlett, C, and Johnson, Ch. (1998) 'Is business English a pidgin?' Language and Intercultural Training 16/1, 4-6.

Bloch, B. and Starks, D. (1999) 'The many faces of English: Intra-language variation and its implications for international business.' Corporate Communications 4/2, 80-88.

Block, D. (2002) 'McCommunication: A problem in the frame for SLA.' In: Block, D. and Cameron, D. (eds) Globalization and Language Teaching. London: Routledge. 117-133.

Boje, D. M. (1991) 'The storytelling organization: A study of story performance in an office-supply firm.' Administrative Science Quarterly 36/1, 106-126.

Bowers, R. (1986) 'English in the world: Aims and achievements in English Language Teaching.' TESOL Quarterly 20/3, 393-410.

Brumfit, C. (2001) Individual Freedom in Language Teaching. Oxford: Oxford University Press.

Brutt-Griffler, J. (2002) World English. A Study of its Development. Clevedon: Multilingual Matters.

Byram, M. (1997a) 'Cultural studies and foreign language teaching.' In: Bassnett, S. (ed.) Studying British Cultures: An Introduction. London: Routledge. 53-64.

Byram, M. (1997b) Teaching and Assessing Intercultural Communicative Competence. Clevedon: Multilingual Matters.

Byram, M. and Cain, A. (1998) 'Civilisation/cultural studies: An experiment in French and English schools'. In: Byram, M. and Fleming, M. (eds) Language Learning in Intercultural Perspective: Approaches through Drama and Ethnography. Cambridge: Cambridge University Press. 32-44.

Canagarajah, S. (1999) Resisting Linguistic Imperialism in English Teaching. Oxford: Oxford University Press.

Cenoz, J. and Jessner, U. (2000) English in Europe. The Acquisition of a Third Language. Clevedon: Multilingual Matters.

Connelly, F. M. and Clandini, D. J. (1990) 'Stories of experience and narrative inquiry.' Educational Researcher 19/5, 2-14.

Council of Europe (2007) Common European Framework of Reference for Languages: Learning, Teaching, Assessment. Cambridge: Cambridge University Press.

Cresswell, J. W. (1998) Qualitative Inquiry and Research Design Choosing Among Five Traditions. London: Sage.

Crystal, D. (1997) The Cambridge Encyclopedia of Language. Cambridge: Cambridge University Press.

Crystal, D. (2003) English as a Global Language. $2^{\text {nd }}$ ed. Cambridge: Cambridge University Press. 
Dörnyei, Z. (2007) Research Methods in Applied Linguistics. Oxford: Oxford University Press.

Dovring, K. (1997) English as a Lingua Franca. Double Talk in Global Persuasion. Westport, CT: Praeger.

Elliot, J. (2005) Using Narrative in Social Research. Qualitative and Quantitative Approaches. London: Sage Publications.

Firth, A. (1996) 'The discursive accomplishment of normality. On 'lingua franca' English and conversation analysis.' Journal of Pragmatics 26/3, 237-259.

Gee, J. P. (1996) 'Discourses and literacies.' In: Gee, J. P. (ed.) Social Linguistics and Literacies: Ideologies and Discourses. London: Farmer Press. 122-160.

Gray, J. (2002) 'The global coursebook in English language teaching.' In: Block, D. and Cameron, D. (eds) Globalization and Language Teaching. London: Routledge. 151-167.

Gudmundsdottir, S. (2001) 'Narrative research on school practice.' In: Richardson, V. (ed.) Handbook of Research on Teaching. $4^{\text {th }}$ ed. Washington, DC: American Educational Research Association. 226-240.

Haegeman, P. (2002) 'Foreigner talk in lingua franca business telephone calls.' In: Knapp, K. and Meikerkord, C. (eds) Lingua Franca Communication. Frankfurt am Mein: Peter Lang. 135-162.

Heikkinen, H. L. T. (2002) 'Whatever is narrative research?' In: Huttunen, R., Heikkinen, H. L. T. and Syrjälä, L. (eds) Narrative Research: Voices from Teachers and Philosophers. Jyväskylä, Finland: SoPhi. 13-25.

House, J. (1999) 'Misunderstanding in intercultural communication: Interactions in English as lingua franca and the myth of mutual intelligibility.' In: Gutzman, C. (ed.) Teaching and Learning English as a Global Language: Native and Non-native Perspectives. Tübingen: Stauffenburg. 73-89.

House, J. (2002) 'Developing pragmatic competence in English as a lingua franca.' In: Knapp, K. and Meikerkord, C. (eds) Lingua Franca Communication. Frankfurt am Mein: Peter Lang. 245-267.

Jenkins, J. (2004) 'Research in teaching pronunciation and intonation.' Annual Review of Applied Linguistics 23/1, 83-103.

Jenkins, J. (2007) English as a Lingua Franca: Attitude and Identity. Oxford: Oxford University Press.

Kachru, B. (1985) 'Standards, codification and sociolinguistic realism: The English language in the outer circle.' In: Quirk, R. and Widdowson, H. G. (eds) English in the World: Teaching and Learning the Language and Literatures. Cambridge: Cambridge University Press. 11-30.

Knapp, K. and Meierkord, Ch. (2002) Lingua Franca Communication. Frankfurt am Mein: Peter Lang.

Kramsch, C. (1998) 'The privilege of the intercultural speaker.' In: Byram, M. and Fleming, M. (eds) Language Learning in Intercultural Perspective. Cambridge: Cambridge University Press. 16-31.

LeCompte, M. D., Preissle, J. and Tesch, R. (1993) Ethnography and Qualitative Design in Educational Research. San Diego, CA: Academic Press.

Lesznyak, A. (2002) 'From chaos to the smallest common denominator. Topic management in English lingua franca communication.' In: Knapp, K. and Meikerkord, C. (eds) Lingua Franca Communication. Frankfurt am Mein: Peter Lang. 163-194.

Llurda, E. (2004) 'Non-native speaker teachers and English as an international language.' International Journal of Applied Linguistics 14/3, 314-323. 
Louhiala-Salminem, L. and Charles, M. (2006) 'English as the Lingua Franca of international business communication: Whose English? What English?' In: PalmerSilveira, J. C., Ruiz-Garrido, M. F. and Fortanet Gómez, I. (eds) Intercultural and International Business Communication. Theory, Research and Teaching. Bern: Peter Lang. 27-54.

Louhiala-Salminen, L. and Kankaanranta, A. (2011) 'Professional communication in a global business context: The notion of global communicative competence.' IEEE Transactions on Professional Communication 54/3, 244-262.

Louhiala-Salminen, L. Charles, M. and Kankaanranta, A. (2005) 'English as a lingua franca in Nordic corporate mergers: Two case companies.' English for Specific Purposes 24/4, 401-421.

May, T. (1993) Social Research: Issues, Methods and Process. Buckingham, UK: Open University Press.

Meierkord, Ch. (2002) 'Language stripped bare or linguistic masala? Culture in lingua franca communication.' In: Knapp, K. and Meierkord, C. (eds) Lingua Franca Communication. Frankfurt am Mein: Peter Lang. 109-134.

Moen, T. (2006) 'Reflections on the narrative research approach.' International Jounal of Qualitative Methods 5/4. Article 1. Online document. 1 July $2012<$ http://www. ualberta.ca/ iiqm/backissues/5 4/pdf/moen.pdf $>$.

Nickerson, C. (2005) 'English as a lingua franca in international business contexts.' English for Specific Purposes 24/4, 367-380.

Niedzielski, N. and Preston, D. (2003) Folk Linguistics. Berlin: Mouton de Gruyter.

Ostler, N. (2005) Empires of the Word: A Language History of the World. New York: Harper Collins.

Paikeday, T. (1985) The Native Speaker is Dead! Toronto: Paikeday Publishing Inc.

Patton, M. Q. (1987) How to Use Qualitative Methods in Evaluation. Newbury Park, CA: Sage.

Pennycook, A. (1998) English and the Discourses of Colonialism. London: Routledge.

Phillipson, R. (1992) Linguistic Imperialism. Oxford: Oxford University Press.

Polkinghorne, D. E. (1988) Narrative Knowing and the Human Sciences. Albany, NY: State University of New York Press.

Poncini, G. (2004) Discursive Strategies in Multicultural Business Meetings. Bern: Peter Lang.

Riessman, C. K. (2008) Narrative Methods for the Human Sciences. Newbury Park, CA: Sage.

Rogerson-Revell, P. (2007) 'Using English for international business: A European case study.' English for Specific Purposes 26/1, 103-120.

Schneider, S. and Barsoux J. L. (2001) Managing Across Cultures. Harlow: Prentice Hall.

Seidlhofer, B. (2000) 'Mind the gap: English as a mother tongue vs. English as a lingua franca.' Vienna English Working Papers 9/1, 51-69. Online document. 9 July 2013 $<\mathrm{http}$ ://www.univie.ac.at/Anglistik/ang new/online papers/views/VIEW00_1.pdf $>$.

Seidlhofer, B. (2001) 'Closing a conceptual gap: The case for a description of English as a lingua franca.' International Journal of Applied Linguistics 11/2, 133-158.

Seidlhofer, B. (2004) 'Research perspectives on teaching English as a lingua franca.' Annual Review of Applied Linguistics 24, 209-239.

Tietze, S. (2008) International Management and Language. London and New York: Routledge.

Vandermeeren, S. (1999) 'English as lingua franca in written corporate communication: Findings from a European survey.' In: Bargiela-Chiappini, F. and Nickerson, C. (eds) Writing Business: Genres, Media and Discourses. Harlow: Pearson. 272-291. 
Victor, D. (1992) International Business Communication. New York: Harper Collins.

Vourela, T. (2004) 'How does a sales team reach goals in intercultural business negotiations? A case study.' English for Specific Purposes 24/1, 65-92.

Vygotsky, L. S. (1978) Mind in Society: The Development of Higher Psychological Processes. Cambridge, MA: Harvard University Press.

Widdowson, H. G. (1994) 'The ownership of English.' TESOL Quarterly 28/2, 377-388.

Zellermayer, M. (1997) 'When we talk about collaborative curriculum-making, what are we talking about?' Curriculum Inquiry 27/2, 187-214.

\section{Appendix. 1}

\section{Transcription conventions}

// Overlapping talk from the first to the last slash.

... A pause of one second or less within an utterance.

(2.0) A pause of more than one second within an utterance or between turns, the number indicates the length of the pause.

*** A deletion

[ ] An explanatory insertion.

Italics A word or part of a word emphasized by a speaker.

Adapted from: Boje, D. M. (1991) 'The storytelling organization: A study of story performance in an office-supply firm.' Administrative Science Quarterly 36/1, 106-126. 